Marquette University

e-Publications@Marquette

Biomedical Engineering Faculty Research and

Publications

Biomedical Engineering, Department of

$10-2013$

\title{
Characterization and Limitations of Diffusion Tensor Imaging Metrics in the Cervical Spinal Cord in Neurologically Intact Subjects
}

\author{
Aditya Vedantam \\ Medical College of Wisconsin \\ Michael B. Jirjis \\ Marquette University \\ Brian D. Schmit \\ Marquette University, brian.schmit@marquette.edu \\ Marjorie C. Wang \\ Medical College of Wisconsin \\ John L. Ulmer \\ Medical College of Wisconsin
}

See next page for additional authors

Follow this and additional works at: https://epublications.marquette.edu/bioengin_fac

Part of the Biomedical Engineering and Bioengineering Commons

\section{Recommended Citation}

Vedantam, Aditya; Jirjis, Michael B.; Schmit, Brian D.; Wang, Marjorie C.; Ulmer, John L.; and Kurpad, Shekar N., "Characterization and Limitations of Diffusion Tensor Imaging Metrics in the Cervical Spinal Cord in Neurologically Intact Subjects" (2013). Biomedical Engineering Faculty Research and Publications. 149.

https://epublications.marquette.edu/bioengin_fac/149 


\section{Authors}

Aditya Vedantam, Michael B. Jirjis, Brian D. Schmit, Marjorie C. Wang, John L. Ulmer, and Shekar N. Kurpad 
Marquette University

e-Publications@Marquette

\section{Biomedical Engineering Faculty Research and Publications/College of} Engineering

This paper is NOT THE PUBLISHED VERSION; but the author's final, peer-reviewed manuscript. The published version may be accessed by following the link in the citation below.

Journal of Magnetic Resonance Imaging, Vol. 38, No. 4 (February 6, 2013): 861-867. DOI. This article is (C) Wiley and permission has been granted for this version to appear in e-Publications@Marquette. Wiley does not grant permission for this article to be further copied/distributed or hosted elsewhere without the express permission from Wiley.

\section{Characterization and Limitations of Diffusion Tensor Imaging Metrics in The Cervical Spinal Cord in Neurologically Intact Subjects}

Aditya Vedantam

Department of Neurosurgery, Medical College of Wisconsin, Milwaukee, Wisconsin Michael B. Jirjis

Department of Biomedical Engineering, Marquette University, Milwaukee, Wisconsin Brian D. Schmit

Department of Biomedical Engineering, Marquette University, Milwaukee, Wisconsin Marjorie C. Wang Department of Neurosurgery, Medical College of Wisconsin, Milwaukee, Wisconsin John L. Ulmer Department of Radiology, Medical College of Wisconsin, Milwaukee, Wisconsin Shekar N. Kurpad 
Department of Neurosurgery, Medical College of Wisconsin, Milwaukee, Wisconsin Spinal Cord Injury Center, Medical College of Wisconsin, Clement J. Zablocki VA Medical Center, Department of Neurosurgery, 9200 W Wisconsin Avenue, Milwaukee, WI

\section{Abstract}

\section{Purpose}

To characterize diffusion tensor imaging (DTI) metrics across all levels of the cervical spinal cord (CSC) and to study the impact of age and signal quality on these metrics.

\section{Materials and Methods}

DTI metrics were calculated for gray matter (GM) and white matter (WM) funiculi throughout the CSC (C1-T1) in 25 healthy subjects (22-85 years old). Signal-to-noise ratios (SNRs) and mean DTI metrics were measured for the upper (C1-3), middle (C4-6) and lower (C7-T1) cervical segments. Age-related changes in DTI metrics were analyzed for the individual segment groups.

\section{Results}

Fractional anisotropy (FA), mean diffusivity (MD) and transverse apparent diffusion coefficient (tADC) showed significant differences between GM and WM funiculi. Significant age-related changes were observed in FA in upper and middle CSC segments but not in the lower CSC. The median SNR was significantly lower in the middle and lower segment groups as compared to the upper levels, contributing to poor spatial resolution in these regions.

\section{Conclusion}

This study provides DTI data for GM and WM funiculi throughout the CSC. While DTI metrics may be used to define cord pathology, variations in metrics due to age and signal quality need to be accounted for before making definitive conclusions. J. Magn. Reson. Imaging 2013;38:861-867. (C) 2013 Wiley Periodicals, Inc.

DIFFUSION TENSOR IMAGING (DTI) provides measures of water molecule diffusion within tissues $\underline{1}$. In neural tissues, water molecules move preferentially along the longitudinal axis of axons. This predominantly unidirectional diffusion of water molecules, termed anisotropy, is characteristic of parallel axonal bundles $\underline{\mathbf{2}}$. In the spinal cord, white matter tracts show high anisotropy, while gray matter, which is predominantly comprised of neuronal cell bodies, demonstrates low anisotropy. The microstructural architecture of the spinal cord produces differences in anisotropy that are visualized on DTI maps, and quantified using DTI metrics.

Prior studies have shown DTI to be a useful imaging technique to characterize spinal cord microstructure in humans $\underline{3}-\underline{6}$. In the cervical spinal cord (CSC), DTI metrics are able to distinguish white matter funiculi and gray matter $\underline{7}-\underline{9}$. DTI metrics in the CSC are also sensitive to age-related microstructural changes $\underline{10}-\underline{13}$. However, the majority of previous studies have evaluated only a few cervical segments in the CSC and therefore, it is unclear if DTI is uniformly sensitive to microstructural anatomy throughout CSC. With the increasing use of DTI in patients with cervical cord pathology, it is essential to determine the current capabilities and limitations of CSC DTI.

To better understand DTI metrics in the cervical cord, we characterized the diffusivities of the central gray matter and individual white matter funiculi across all levels of the cervical cord in a set of neurologically intact subjects. We analyzed how DTI metrics were affected by age and signal quality in different cervical segments. 


\section{MATERIALS AND METHODS}

\section{Subjects}

Informed consent was obtained before enrolling subjects, and the procedure was approved by the appropriate Institutional Review Boards. We selected 25 subjects with a normal neurological exam and no medical implants. At least one subject was chosen for each decade between 20 and 90 years.

\section{Image Acquisition}

Diffusion weighted images were obtained throughout the cervical spine (C1-T1) using a single-shot, twicerefocused, spin-echo echo planar image (SE-EPI) pulse sequence. Images were acquired on a 1.5 Tesla (T) clinical MR scanner (Signa Excite; GE Medical Systems, Milwaukee, WI) with the use of a CTL spine coil (GE Medical Systems). Axial slices perpendicular to the long axis of the spinal cord were acquired, with diffusion gradients in 25 equidistant directions with $a b=500 \mathrm{~s} / \mathrm{mm}^{2}$ and a single T2-weighted $\left(b=0 \mathrm{~s} / \mathrm{mm}^{2}\right)$ image. Slices were $3 \mathrm{~mm}$ thick with a 3-mm space gap in between each slice. Diffusion weighted images were obtained with a TR/TE = $4500 / 80 \mathrm{~ms}$, number of excitations $=2$, matrix size $=128 \times 128$ and the FOV was set at $260 \mathrm{~mm} \times 260 \mathrm{~mm}$. For reference, sagittal T2W images were acquired using a TR/TE $=2600 / 110 \mathrm{~ms}$, matrix size of $512 \times 512$, and the FOV was set at $220 \mathrm{~mm} \times 220 \mathrm{~mm}$. Axial T2W images sections were determined from anatomical landmarks on sagittal images and acquired with TR/TE $=500 / 8.4 \mathrm{~ms}$; number of excitations $=1.5$ and matrix size of $512 \times 512$.

\section{Image Processing}

Images were processed using the Analysis of Functional Neurolmages processing suite

(AFNI, http://afni.nimh.nih.gov/afni/). A Fourier transform-based affine registration of the DWIs to the T2weighted image (used in previous clinical studies) 14, 15 was done to correct geometric distortions associated with susceptibility variations, eddy currents and subject motion. Subjects that produced large bulk movements were rescanned. The registered image volume was then processed using AFNI to identify the eigenvalues of the tensor for each voxel.

A constraint nonlinear tensor-fitting algorithm was used to iteratively compute DTI indices. Outliers were checked for in the diffusion images, and were excluded from further analysis. Optimization was completed using a gradient descent method. None of the recorded images were obtained with an SNR $<2$ and thus the bias due to rician noise distribution was considered minimal $\underline{16}$. Moreover, applying a Rician filter for the first 10 subjects did not produce significantly different DTI indices, and therefore this was not performed on the final set of 25 subjects.

DTI indices were calculated from the eigenvalues as follows: fractional anisotropy (FA, defined by Pierpaoli et al) 17, mean diffusivity ( $\mathrm{MD}\left(\times 10^{-3} \mathrm{~mm}^{2} \mathrm{~s}^{-1}\right)$, average of all three eigenvalues), longitudinal transverse apparent diffusion coefficient $\left(\operatorname{IADC}\left(\times 10^{-3} \mathrm{~mm}^{2} \mathrm{~s}^{-1}\right)\right.$, largest eigenvalue), and transverse apparent diffusion coefficient $\left(\operatorname{tADC}\left(\times 10^{-3} \mathrm{~mm}^{2} \mathrm{~s}^{-1}\right)\right.$, average of two smallest eigenvalues).

\section{Regions of Interest (ROIs)}

Images were imported into MATLAB (MathWorks, Natick, MA) and one to three slices per cervical level were selected for analysis. Slices with large susceptibility artifacts were excluded from analysis. ROls for the white matter were traced manually for the ventral funiculus, lateral funiculi, dorsal funiculus and central gray matter in a manner similar to that described by Pattany et al $\underline{18}$ (Fig. 1 ). The ROls were traced in such a manner so as to exclude at least two voxels outside cord, thereby minimizing the risk of partial volume effects due to CSF. The measurements from the right and left lateral funiculi were averaged and the combined value was used in the analysis, as has been reported previously $\underline{7} \underline{8}$. 


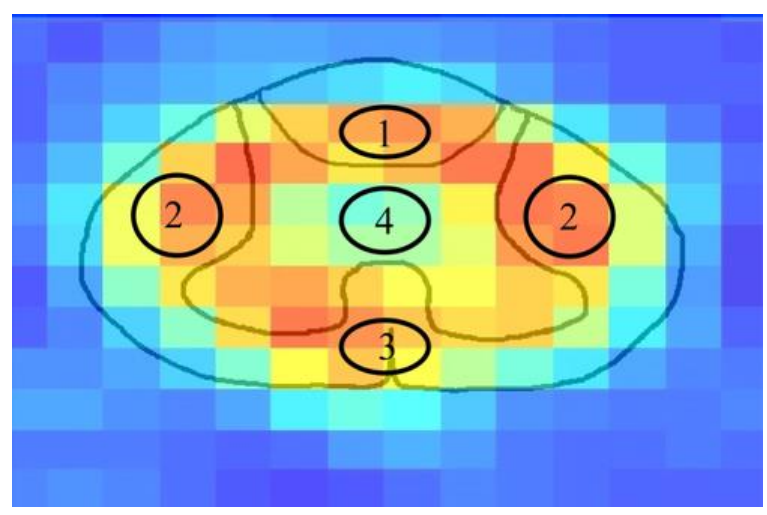

Figure 1 Schematic diagram of a cross-section of the cervical cord superimposed on an axial FA map of the cervical spinal cord in a representative subject. 1, ventral funiculus; 2 , lateral funiculi; 3 , dorsal funiculus; 4 , central gray matter.

The cervical cord was divided into three segmental groups: upper cord (upper border of C1- lower border of C3), middle cord (upper border of C4- lower border of (6), and lower cord (upper border of C7- lower border of T1). The DTI indices of each segmental group were averaged to identify whether different segmental groups of the cord showed significant age-related changes. The SNR was calculated for throughout the CSC in each subject using the method described by Kaufman et al $\underline{19}$. SNR was calculated on T2-weighted images after distortion correction. Signal ROIs were selected at a consistent location inside the body, while noise ROls were selected outside the body (in air), and were obtained at least 10 voxels away from the borders of the image.

\section{Statistical Analysis}

Data were analyzed statistically using SPSS 20.0 (Chicago, IL). DTI measures of the individual funiculi were compared using a one-way analysis of variance (ANOVA) and comparisons between pairs of funiculi were performed using a Tukey post hoc test. Nonparametric tests were used to compare SNR data, which were not normally distributed. Pearson's correlation was used to test for correlations between age and DTI metrics. For statistically significant correlations, Lowess curves (a locally weighted least squares smoothing method) that used $50 \%$ of the data points were drawn to determine data patterns. Regression analysis was performed to statistically define age-related changes in DTI metrics. Data are reported as means \pm SD and the level of significance was set as $P<0.05$.

\section{RESULTS}

Twenty-five healthy subjects ( 12 men and 13 women; age range, 22-85 years) were selected for the study (Table 1). No subject showed significant cord compression or intramedullary hyperintensities on T2W images. Axial FA maps in a representative subject are compared with corresponding axial T2W images in Figure $\underline{\mathbf{2}}$. 


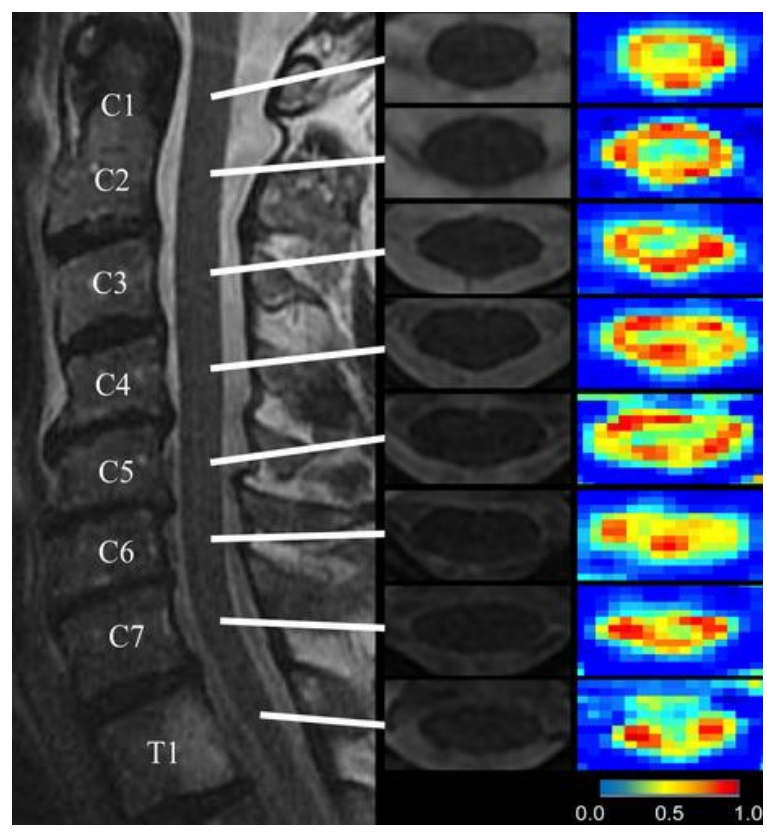

Figure 2 Sagittal T2W MR image (left) of the cervical spine in a normal subject with the corresponding axial T2W images at each cervical level (middle). FA maps (right) at each cervical level show the cross-sectional anatomy with lower anisotropy in the central gray matter and higher anisotropy in the white matter funiculi. Lower cervical segments show poorer spatial resolution as compared to superior levels. [Color figure can be viewed in the online issue, which is available at wileyonlinelibrary.com.]

Table 1. Age-Distribution of Subjects $(n=25)$

\begin{tabular}{|l|l|l|l|}
\hline Age groups (years) & Male & Female & Total \\
\hline $20-29$ & 2 & 1 & 3 \\
\hline $30-39$ & 2 & 3 & 5 \\
\hline $40-49$ & - & 1 & 1 \\
\hline $50-59$ & 2 & 1 & 3 \\
\hline $60-69$ & 1 & 3 & 4 \\
\hline $70-79$ & 3 & 2 & 5 \\
\hline $80-89$ & 2 & 2 & 4 \\
\hline
\end{tabular}

\section{DTI Metrics of the White Matter}

The mean FA, MD, IADC and tADC of all white matter tracts was $0.75 \pm 0.04,0.78 \pm 0.1 \times 10^{-3} \mathrm{~mm}^{2} \mathrm{~s}^{-1}, 1.64 \pm 0.2$ $\times 10^{-3} \mathrm{~mm}^{2} \mathrm{~s}^{-1}$ and $0.35 \pm 0.08 \times 10^{-3} \mathrm{~mm}^{2} \mathrm{~s}^{-1}$, respectively. Mean DTI metrics of the individual white matter bundles are shown in Table 2. FA of the ventral, lateral, and dorsal funiculi decreased in a rostral to caudal direction (Spearman's $r=-0.90,-0.85$, and -0.97 respectively, $P<0.01$ ).

Table 2. Mean DTI Metrics ( $\pm S D$ ) of the Gray Matter and Individual White Matter Funiculi in the Cervical Spinal Cord of 25 Neurologically Intact Subjects

\begin{tabular}{|l|l|l|l|l|l|l|l|}
\hline & DTI Metrics & $\begin{array}{l}\text { Whole } \\
\text { cord }\end{array}$ & $\begin{array}{l}\text { Ventral } \\
\text { funiculus (I) }\end{array}$ & $\begin{array}{l}\text { Lateral } \\
\text { funiculi (II) }\end{array}$ & $\begin{array}{l}\text { Dorsal } \\
\text { funiculus (III) }\end{array}$ & $\begin{array}{l}\text { Central } \\
\text { gray matter }\end{array}$ & $\begin{array}{l}\text { Differences } \\
\text { between funiculi }\end{array}$ \\
\hline a. & FA & $\begin{array}{l}0.63 \\
(0.03)\end{array}$ & $0.72(0.03)$ & $0.78(0.03)$ & $0.76(0.03)$ & $0.51(0.03)$ & la vs Ila, Illaa \\
\hline
\end{tabular}




\begin{tabular}{|c|c|c|c|c|c|c|c|}
\hline b. & $\begin{array}{l}\mathrm{MD}\left(\mathrm{x} 10^{-}\right. \\
\left.{ }^{3} \mathrm{~mm}^{2} \mathrm{~s}^{-1}\right)\end{array}$ & $\begin{array}{l}0.98 \\
(0.09)\end{array}$ & $0.74(0.1)$ & 0.75 (0.09) & $0.86(0.1)$ & $0.99(0.09)$ & Illb vs Ib, Ilbb \\
\hline c. & $\begin{array}{l}\text { IADC (x10- } \\
\left.{ }^{3} \mathrm{~mm}^{2} \mathrm{~s}^{-1}\right)\end{array}$ & $\begin{array}{l}1.77 \\
(0.1)\end{array}$ & $1.5(0.2)$ & $1.61(0.1)$ & $1.82(0.2)$ & $1.62(0.1)$ & IIIc vs Ic, IIc $\underline{b}$ \\
\hline d. & $\begin{array}{l}\text { tADC }\left(\times 10^{-}\right. \\
\left.{ }^{3} \mathrm{~mm}^{2} \mathrm{~s}^{-1}\right)\end{array}$ & $\begin{array}{l}0.59 \\
(0.08)\end{array}$ & $0.36(0.09)$ & $0.31(0.07)$ & $0.38(0.08)$ & $0.68(0.06)$ & IIId vs IIda \\
\hline
\end{tabular}

$\mathrm{FA}=$ fractional anisotropy; $\mathrm{MD}=$ mean diffusivity; $I \mathrm{ADC}=$ longitudinal apparent diffusion coefficient; $\mathrm{tADC}=$ transverse apparent diffusion coefficient.

a $P<0.05$.

${ }^{b} P<0.001$.

\section{Comparison of DTI Metrics Between Funiculi}

One-way ANOVA indicated significant differences between the white matter bundles with regard to the FA $(P<$ $0.001), \operatorname{MD}(P=0.001), \operatorname{IADC}(P<0.001)$, and $\operatorname{tADC}(P=0.016)$. The MD and IADC of the dorsal funiculi were the highest among all white matter bundles (Tukey test; $P<0.05$ ). The mean FA of the ventral funiculus was the lowest among the three white matter compartments (Tukey test; $P<0.05$ ). Other differences between individual funiculi throughout the CSC are shown in Table $\underline{2}$.

\section{Gray Matter}

The mean diffusion metrics of the central gray matter are shown in Table $\underline{2}$. The gray matter FA, MD, and tADC were significantly different from the white matter bundles (Tukey test, $p<0.01$ ) (Fig. $\underline{3}$ ). The FA of the gray matter increased in a rostral to caudal direction (Spearman's correlation: $r=0.83, P<0.01$ ). Table $\underline{3}$ shows consistent regional differences between DTI metrics of GM and individual WM funiculi. 

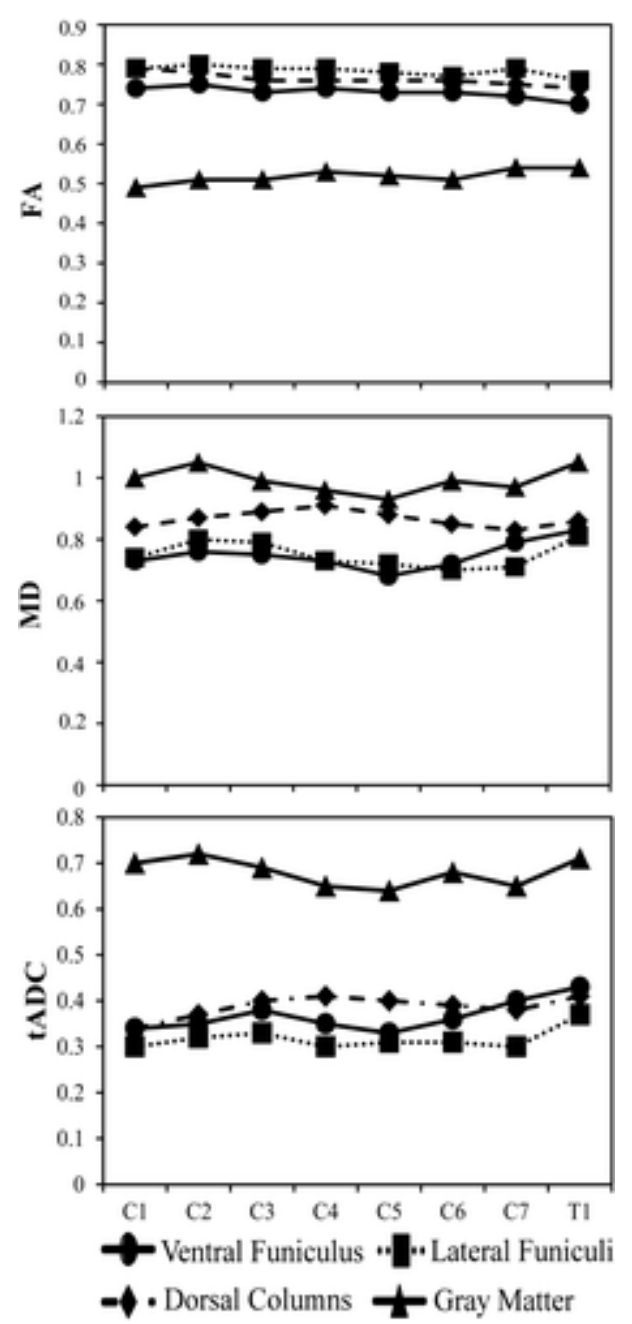

Figure 3 A-C: Mean FA, MD $\left(\times 10^{-3} \mathrm{~mm}^{2} \mathrm{~s}^{-1}\right)$ and $\operatorname{tADC}\left(\times 10^{-3} \mathrm{~mm}^{2} \mathrm{~s}^{-1}\right)$ of the ventral, lateral, dorsal funiculi as well as central gray matter across the cervical cord (C1-T1).

Table 3. Comparisons of Mean DTI Metrics of WM Funiculi and Central Gray Matter in Different Segmental Groups of the Cervical Spinal Cord*

\begin{tabular}{|l|l|l|l|}
\hline & UPPER (C1-C3) & MIDDLE (C4-C6) & LOWER (C7-T1) \\
\hline FA & & & \\
\hline VF vs GM & $<0.001$ & $<0.001$ & 0.001 \\
\hline LF vs GM & $<0.001$ & $<0.001$ & $<0.001$ \\
\hline DC vs GM & $<0.001$ & $<0.001$ & $<0.001$ \\
\hline MD & & & \\
\hline VF vs GM & $<0.001$ & $<0.001$ & 0.04 \\
\hline LF vs GM & $<0.001$ & $<0.001$ & 0.02 \\
\hline DC vs GM & 0.001 & 0.02 & - \\
\hline IADC & & & \\
\hline VF vs GM & - & - & - \\
\hline LF vs GM & - & - & - \\
\hline DC vs GM & 0.003 & 0.001 & - \\
\hline tADC & & & \\
\hline VF vs GM & $<0.001$ & $<0.007$ & 0.006 \\
\hline
\end{tabular}




\begin{tabular}{|l|l|l|l|}
\hline LF vs GM & $<0.001$ & $<0.001$ & 0.002 \\
\hline DC vs GM & $<0.001$ & $<0.001$ & 0.005 \\
\hline
\end{tabular}

$P$ values $<0.05$ for individual comparisons are displayed.

$\mathrm{FA}=$ fractional anisotropy; $\mathrm{MD}=$ mean diffusivity $\left(\times 10^{-3} \mathrm{~mm}^{2} \mathrm{~s}^{-1}\right) ; I A D C=$ longitudinal apparent diffusion coefficient $\left(\times 10^{-3} \mathrm{~mm}^{2} \mathrm{~s}^{-1}\right)$; tADC $=$ transverse apparent diffusion coefficient $\left(\times 10^{-3} \mathrm{~mm}^{2} \mathrm{~s}^{-1}\right)$; VF = ventral funiculus; LF = lateral funiculi; DC = dorsal columns; GM- gray matter; $-=$ no significant difference.

\section{Change in DTI Metrics With Age}

The FA of the entire cervical cord (C1-T1), upper and middle cervical segments showed a significant inverse correlation with age (Pearson's coefficient $=-0.55,-0.4,-0.64, P<0.05$, respectively). Lowess curves showed a bilinear change in FA with age with a rapid decrease in FA after the age of 55 years (Fig. 4). Regression analysis showed that FA was linearly associated with age in subjects over the age of 55 (Fig. 4), while there was no significant association in younger subjects. The lower cord FA did not show any significant correlation with age. Other DTI metrics also did not correlate with age.
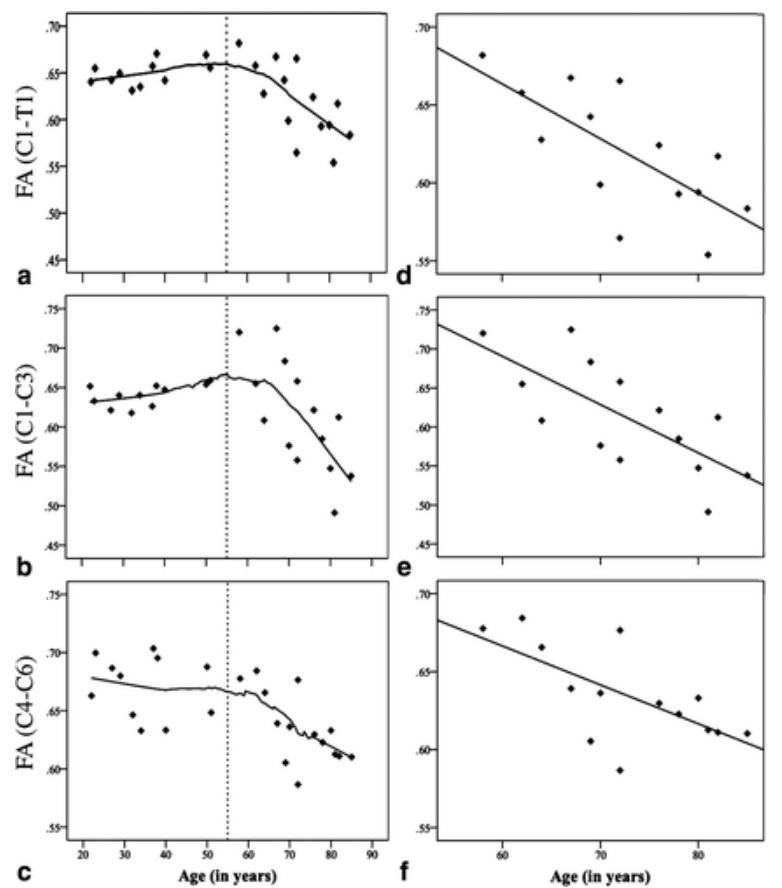

Figure 4 Scatter plots showing the relationship of FA with age. a-c: Lowess curves drawn on scatter plots for all

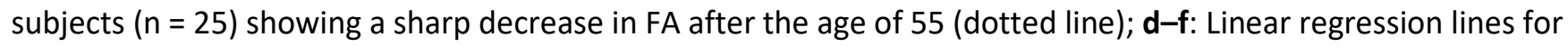
entire cervical spinal cord $\left(R^{2}=0.5 ; P=0.004\right)$, upper cervical cord $\left(R^{2}=0.52 ; P=0.003\right)$, and middle cervical $\operatorname{cord}\left(R^{2}=0.44 ; P=0.009\right)$, showing FA as a function of age in subjects $>55$ years $(n=14)$.

\section{Gender Differences}

No significant differences were found between male $(n=12)$ and female $(n=13)$ subjects in whole cord, gray and white matter DTI metrics from C1-T1 (Student t test, $P>0.05$ ).

\section{SNR}

The median SNR of the diffusion images across all levels was 7.3 (inter-quartile range 2.8). The median (IQR) SNR of the upper, middle, and lower cervical cord segments were 10.6 (4.8), 5.8 (3.6) and 5.3 (2.4), respectively. The SNR significantly differed between the upper (C1-3), middle (C4-6), and lower cervical cord (C7-T1) (KruskalWallis; $P<0.001)$. The upper cord had significantly higher SNR compared with the middle and lower cord (Mann- 
Whitney; $P<0.001$ ). The middle and lower cords had comparable SNRs (Mann-Whitney test; $P=0.19$ ). SNRs throughout the CSC of individual subjects are shown in Figure $\underline{5}$.

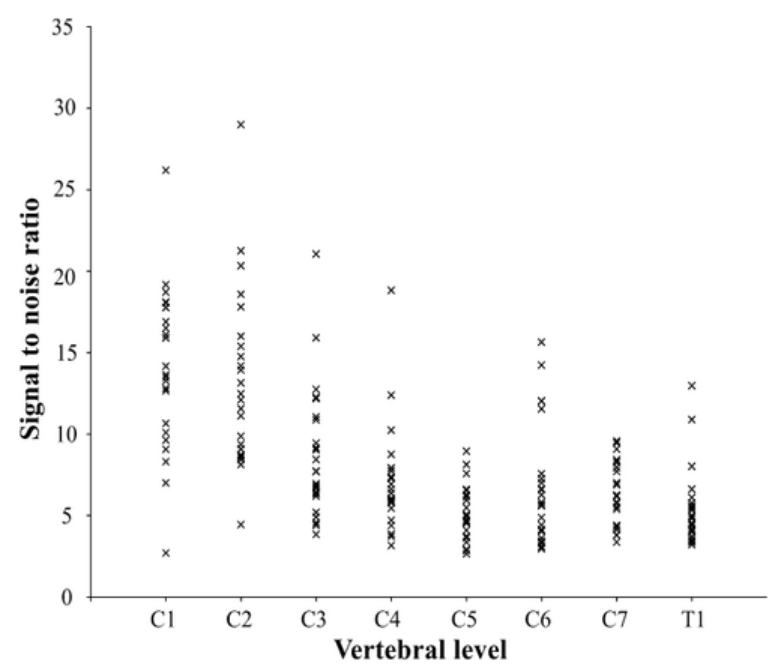

Figure 5 Distribution of signal to noise ratios (SNRs) throughout the cervical spinal cord (C1-T1) showing a rostro-caudal decrease in SNR. "X" denotes the SNR for an individual subject at that particular vertebral level.

\section{DISCUSSION}

The present study has three major findings: (i) FA, MD, and tADC differ between gray and white matter, as well as between individual white matter funiculi across all levels of the cervical spinal cord; (ii) Age-related decreases in FA of the CSC are detected specifically in the upper and middle CSC; (iii) Reductions in SNR are observed in a rostral to caudal direction.

Previous authors have measured the diffusivities of gray and white matter in the normal human spinal cord 7$\underline{9}, \underline{14}, \underline{20}-22 ;$ however, only few studies, with limited number of subjects (8-11 subjects), have documented DTI metrics of the individual white matter funiculi in the CSC $\underline{7}-\underline{9}$. The mean white matter FA in our study was similar to some previously reported values in the cervical cord $\underline{\mathbf{8}}, \underline{\mathbf{2 2}}$, but higher than others. $\underline{\mathbf{2}} \underline{\mathbf{2 0}}$ The larger sample size and wider age range in this study could account for minor variations in the measured DTI metrics. Similar to previous reports $\underline{7}, \underline{23}-\underline{25}$, we found that the ventral funiculus had the lowest FA among all white matter bundles. The FA of each funiculus decreased in a rostro-caudal direction as has been shown previously with regard to whole cord FA values $\underline{11}, \underline{12}$. The rostro-caudal decrease in FA in our study, however, is less pronounced and may be partly attributed to the overestimation of FA in regions of low SNR (lower CSC) at b values closer to $1000 \mathrm{~s} \mathrm{~mm}^{-2} \underline{26}$. It is possible that because several white matter tracts terminate in the cervical enlargement, the uniform longitudinal alignment of white matter fibers is disturbed in the lower cervical cord leading to a decrease in FA.

Post mortem 27-31 and other imaging studies $\underline{32}, \underline{33}$ have described age-related degenerative changes in the spinal cord such as neuronal loss, astrocytosis, demyelination, and decreased spinal cord volume. The FA of the upper CSC has been shown to decrease with age $\underline{10}, \underline{11}$. Similar to Agosta et al $\underline{10}$, we found the FA of the CSC to decrease rapidly in older subjects. These results further substantiate the sensitivity of FA to age-related changes in the spinal cord, and indicate the need for selecting controls of similar ages when studying spinal cord pathology. We believe that the relationship between FA and age, particularly in the lower cord, was affected by the differences in SNR across the cervical segments. The lower SNR may have produced minor variations in DTI metrics that affected the correlational analysis with age. 
The present study has brought out important limitations with regards to CSC DTI. The SNR in the C4-T1 segments was significantly lower than that of the upper CSC (C1-C3). It is likely that the construct of the surface coil 34 as well as body morphology negatively impact the signal intensity in these segments. One outcome of low SNRs is the overestimation of FA (at b values approaching $1000 \mathrm{~s} \mathrm{~mm}^{-2}$ ) $\underline{\mathbf{1 7}}, \underline{\mathbf{2 6}}$, particularly in areas of low anisotropy $\underline{35}, \underline{36}$ such as the central gray matter. This may explain the rostral to caudal increase in FA of the gray matter, which was found in this study. We did not try signal-averaging to increase the accuracy of our measurements, because this has been shown to be incapable of correcting such errors $\underline{16}$. Nevertheless, our findings are similar to the mean gray matter FA in other studies (within 2 SDs) $\underline{\mathbf{8}}, \underline{14}, \underline{22}$.

Although significant differences in DTI metrics between GM and WM were seen consistently across the CSC, poor spatial resolution in the lower CSC meant that tracing ROls within specific regions of the spinal cord were prone to partial volume effects. Our study may have benefitted from the use of a 3T MR scanner, which has been shown to produce images with better resolution $\underline{37}$ and higher signal-to-noise ratio $\underline{38}$. While DTI metrics are not directly affected by field strength $\underline{37}, \underline{39}$, a higher field strength would improve the precision of DTI measurements $\underline{39}$, increase the contrast between GM and WM regions $\underline{37}$, and facilitate more accurate tracing of ROls within the spinal cord.

The trend in SNR values across the CSC has important implications when evaluating spinal cord pathology in the middle and lower CSC. In particular, DTI metrics in patients with cervical spondylotic myelopathy (CSM), which commonly affects the C4-C7 segments, can potentially be altered by variations in SNR. Minor differences between individual patients and controls may also be created by variations in SNR. Additionally, correlational analysis with clinical outcomes can be affected by the differences in SNRs. While future studies should try to address the technical problems described in our study, it is important that investigators who presently use CSC DTI account for variations in SNR when analyzing their results.

In conclusion, this study provides DTI data for the GM and individual WM funiculi throughout the CSC in neurologically intact subjects. While DTI metrics may be used to define cord pathology, variations in metrics due to age and signal quality need to be accounted for before making definitive conclusions.

\section{REFERENCES}

1 Basser PJ, Mattiello J, LeBihan D. MR diffusion tensor spectroscopy and imaging. Biophys J 1994; 66: $259-267$.

2 Beaulieu $C$. The basis of anisotropic water diffusion in the nervous system - a technical review. NMR Biomed 2002; 15: 435- 455.

3 Clark CA, Barker GJ, Tofts PS. Magnetic resonance diffusion imaging of the human cervical spinal cord in vivo. Magn Reson Med 1999; 41: 1269- 1273.

4 Bammer R, Fazekas F, Augustin M, et al. Diffusion-weighted MR imaging of the spinal cord. AJNR Am J Neuroradiol 2000; 21: 587- 591.

5 Ries M, Jones RA, Dousset V, Moonen CT. Diffusion tensor MRI of the spinal cord. Magn Reson Med 2000; 44: 884- 892.

6 Cercignani M, Horsfield MA, Agosta F, Filippi M. Sensitivity-encoded diffusion tensor MR imaging of the cervical cord. AJNR Am J Neuroradiol 2003; 24: 1254- 1256.

7 Onu M, Gervai P, Cohen-Adad J, et al. Human cervical spinal cord funiculi: investigation with magnetic resonance diffusion tensor imaging. J Magn Reson Imaging 2010; 31: 829-837.

8 Rossi C, Boss A, Steidle G, et al. Water diffusion anisotropy in white and gray matter of the human spinal cord. J Magn Reson Imaging 2008; 27: 476- 482.

9 Smith SA, Jones CK, Gifford A, et al. Reproducibility of tract-specific magnetization transfer and diffusion tensor imaging in the cervical spinal cord at 3 tesla. NMR Biomed 2010; 23: 207- 217.

10 Agosta F, Lagana M, Valsasina $\mathrm{P}$, et al. Evidence for cervical cord tissue disorganisation with aging by diffusion tensor MRI. Neuroimage 2007; 36: 728- 735. 
11 Mamata H, Jolesz FA, Maier SE. Apparent diffusion coefficient and fractional anisotropy in spinal cord: age and cervical spondylosis-related changes. J Magn Reson Imaging 2005; 22: 38-43.

12 Van Hecke W, Leemans A, Sijbers J, Vandervliet E, Van Goethem J, Parizel PM. A tracking-based diffusion tensor imaging segmentation method for the detection of diffusion-related changes of the cervical spinal cord with aging. J Magn Reson Imaging 2008; 27: 978- 991.

13 Lindberg PG, Feydy A, Maier MA. White matter organization in cervical spinal cord relates differently to age and control of grip force in healthy subjects. J Neurosci 2010; 30: 4102-4109.

14 Ellingson BM, Ulmer JL, Kurpad SN, Schmit BD. Diffusion tensor MR imaging of the neurologically intact human spinal cord. AJNR Am J Neuroradiol 2008; 29: 1279- 1284.

15 Ellingson BM, Ulmer JL, Kurpad SN, Schmit BD. Diffusion tensor MR imaging in chronic spinal cord injury. AJNR Am J Neuroradiol 2008; 29: 1976- 1982.

16 Gudbjartsson H, Patz S. The Rician distribution of noisy MRI data. Magn Reson Med 1995; 34: 910- 914.

17 Pierpaoli C, Basser PJ. Toward a quantitative assessment of diffusion anisotropy. Magn Reson Med 1996; 36: 893- 906.

18 Pattany PM, Puckett WR, Klose KJ, et al. High-resolution diffusion-weighted MR of fresh and fixed cat spinal cords: evaluation of diffusion coefficients and anisotropy. AJNR Am J Neuroradiol 1997; 18: 1049- 1056.

19 Kaufman L, Kramer DM, Crooks LE, Ortendahl DA. Measuring signal-to-noise ratios in MR imaging. Radiology 1989; 173: 265- 267.

20 Mamata H, De Girolami U, Hoge WS, Jolesz FA, Maier SE. Collateral nerve fibers in human spinal cord: visualization with magnetic resonance diffusion tensor imaging. Neuroimage 2006; 31: 24- 30.

21 Holder CA, Muthupillai R, Mukundan S Jr, Eastwood JD, Hudgins PA. Diffusion-weighted MR imaging of the normal human spinal cord in vivo. AJNR Am J Neuroradiol 2000; 21: 1799- 1806.

22 Wilm BJ, Gamper U, Henning A, Pruessmann KP, Kollias SS, Boesiger P. Diffusion-weighted imaging of the entire spinal cord. NMR Biomed 2009; 22: 174- 181.

23 Takahashi M, Hackney DB, Zhang G, et al. Magnetic resonance microimaging of intraaxonal water diffusion in live excised lamprey spinal cord. Proc Natl Acad Sci U S A 2002; 99: 16192- 16196.

24 Madi S, Hasan KM, Narayana PA. Diffusion tensor imaging of in vivo and excised rat spinal cord at $7 \mathrm{~T}$ with an icosahedral encoding scheme. Magn Reson Med 2005; 53: 118- 125.

25 Gullapalli J, Krejza J, Schwartz ED. In vivo DTI evaluation of white matter tracts in rat spinal cord. J Magn Reson Imaging 2006; 24: 231- 234.

26 Jones DK, Basser PJ. "Squashing peanuts and smashing pumpkins": how noise distorts diffusion-weighted MR data. Magn Reson Med 2004; 52: 979- 993.

27 Terao S, Sobue G, Hashizume Y, Shimada N, Mitsuma T. Age-related changes of the myelinated fibers in the human corticospinal tract: a quantitative analysis. Acta Neuropathol 1994; 88: 137- 142.

28 Nagayoshi K, Kimura S, Ochi M, et al. Diffusion-weighted echo planar imaging of the normal human cervical spinal cord. J Comput Assist Tomogr 2000; 24: 482.

29 Terao S, Sobue G, Hashizume Y, Li M, Inagaki T, Mitsuma T. Age-related changes in human spinal ventral horn cells with special reference to the loss of small neurons in the intermediate zone: a quantitative analysis. Acta Neuropathol 1996; 92: 109- 114.

30 Cruz-Sanchez F, Moral A, Tolosa E, De Belleroche J, Rossi M. Evaluation of neuronal loss, astrocytosis and abnormalities of cytoskeletal components of large motor neurons in the human anterior horn in aging. $J$ Neural Transm 1998; 105: 689- 701.

31 Bailey AA. Changes with age in the spinal cord. AMA Arch Neurol Psychiatry 1953; 70: 299- 309.

32 Yanase M, Matsuyama Y, Hirose K, et al. Measurement of the cervical spinal cord volume on MRI. J Spinal Disord Tech 2006; 19: 125.

33 Ishikawa M, Matsumoto M, Fujimura Y, Chiba K, Toyama Y. Changes of cervical spinal cord and cervical spinal canal with age in asymptomatic subjects. Spinal Cord 2003; 41: 159- 163.

34 Wheeler-Kingshott CA, Hickman SJ, Parker GJ, et al. Investigating cervical spinal cord structure using axial diffusion tensor imaging. Neuroimage 2002; 16: 93-102. 
35 Bastin ME, Armitage PA, Marshall I. A theoretical study of the effect of experimental noise on the measurement of anisotropy in diffusion imaging. Magn Reson Imaging 1998; 16: 773- 785.

36 Mamata $\mathrm{H}$, Jolesz FA, Maier SE. Characterization of central nervous system structures by magnetic resonance diffusion anisotropy. Neurochem Int 2004; 45: 553- 560.

37 Rossi C, Boss A, Lindig T, et al. Diffusion tensor imaging of the spinal cord at 1.5 and 3.0 Tesla. Rofo 2007; 179: 219.

38 Carballido-Gamio J, Xu D, Newitt D, Han ET, Vigneron DB, Majumdar S. Single-shot fast spin-echo diffusion tensor imaging of the lumbar spine at 1.5 and 3 T. Magn Reson Imaging 2007; 25: 665- 670.

39 Polders DL, Leemans A, Hendrikse J, Donahue MJ, Luijten PR, Hoogduin JM. Signal to noise ratio and uncertainty in diffusion tensor imaging at 1.5, 3.0, and 7.0 Tesla. J Magn Reson

Imaging 2011; 33: 1456- 1463. 